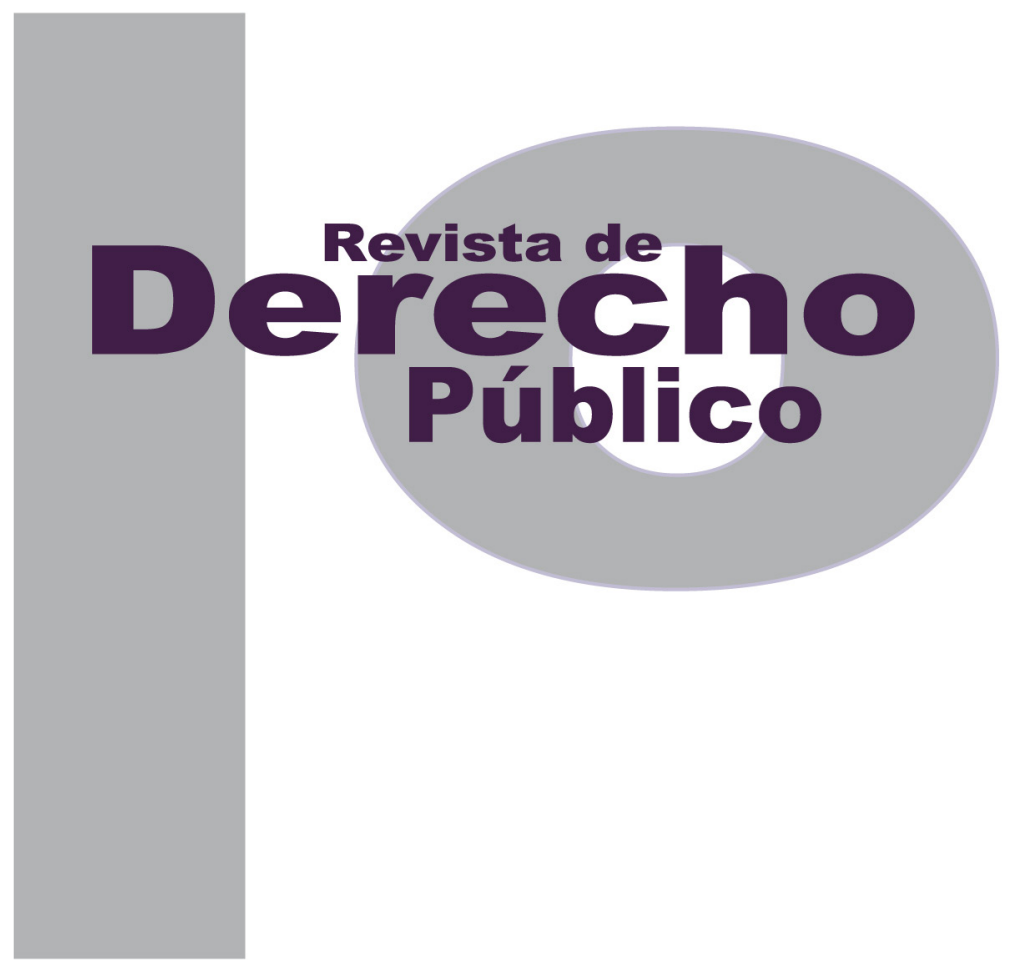

\title{
EL EXHORTO AL LEGISLADOR: ANÁLISIS EN LA JURISPRUDENCIA DE LA CORTE CONSTITUCIONAL COLOMBIANA
}

\author{
ANDREA Celemín CAicedo
}

Artículo de reflexión

DOI: http://dx.doi.org/10.15425/redepub.36.2016.04

Universidad de los Andes

Facultad de Derecho

Rev. derecho publico No. 36

enero - junio de 2016. e-ISSN 1909-7778 


\section{El exhorto al legislador: análisis en la jurisprudencia de la Corte Constitucional colombiana Resumen}

El presente ensayo describe la manera como, mediante su jurisprudencia, la Corte Constitucional se ha relacionado con el órgano legislativo colombiano, y ha utilizado mecanismos como el exhorto al legislador para dar solución a los silencios que generan omisiones legislativas inconstitucionales. Mediante el análisis de la producción jurisprudencial de la Corte sobre el exhorto al legislador se identifican los distintos usos que el alto tribunal le ha dado a esta figura, y se llega a sostener que a pesar de que ninguna norma de la Constitución colombiana de 1991 determinó fórmulas para solucionar las omisiones legislativas inconstitucionales, la Corte no se ha abstenido de identificar tales omisiones y de enviar mensajes al legislador para que profiera las normas necesarias para completar el ordenamiento jurídico colombiano. Estos mensajes varían en su tono y van desde respetuosas y prudentes recomendaciones al legislador hasta invasiones a la órbita de competencias del órgano legislativo.

Palabras claves: silencio legislativo, omisión legislativa, exhorto al legislador, activismo judicial.

\section{Exhortation to the congress: analysis in the colombian Constitutional Court decisions}

\section{Abstract}

This paper describes relations between the Constitutional Court and the Colombian Congress in cases of legislative omissions. The essay analyses modes in which the jurisprudence of the Colombian Constitutional Court uses mechanism such as exhortation to the Congress in order to find a way for resolving cases of legislative omissions. Although there is no norm in the 1991 Colombian Constitution that includes legislative omission and its treatment, the Colombian Constitutional Court uses the exhortation as a mechanism to solve this sort of problems in completeness and coherence of the Colombian juridical system. Also, the analysis identifies tones used by the Colombian Constitutional Court in order to resolve the legislative omission; sometimes the exhortation to the parliament is just rhetorical and extremely respectful of the legislative branch powers. In other opportunities, the exhortation to the parliament looks like a truly invasions in the Congress competence sphere.

Keywords: legislative silence, legislative omission, exhortation to the Congress, judicial activism.

\section{0 exorto ao legislador: análise na jurisprudência da Corte Constitucional colombiana}

\section{Resumo}

O presente ensaio descreve a maneira como, mediante sua jurisprudência, a Corte Constitucional tem se relacionado com o órgão legislativo colombiano, e tem utilizado mecanismos como o exorto ao legislador para dar solução aos silêncios que geram omissões legislativas inconstitucionais. Mediante a análise da produção jurisprudencial da Corte sobre o exorto ao legislador se identificam os distintos usos que o alto tribunal tem dado a esta figura, e se afirma que apesar de que nenhuma norma da Constituição colombiana de 1991 determinou fórmulas para resolver as omissões legislativas inconstitucionais, a Corte não tem se abstêmio de identificar tais omissões e de enviar mensagens ao legislador para que profira as normas necessárias para completar o ordenamento jurídico colombiano. Estas mensagens variam em seu tom e vão desde respeitosas e prudentes recomendações ao legislador até invasões à órbita de competências do órgão legislativo.

Palavras-chaves: silêncio legislativo, omissão legislativa, exorto ao legislador, ativismo judicial. 


\title{
El exhorto al legislador: análisis en la jurisprudencia de la Corte Constitucional colombiana*
}

\author{
AndRea Celemín Caicedo**
}

\section{SUMARIO}

Introducción - I. DESARROLLO DE LA REFLEXIÓN - II. ¿CÓMO LIDIAR CON LOS SILENCIOS DEL LEGISLADOR CUANDO SE TORNAN OMISIONES INCONSTITUCIONALES? - A. Primera fórmula: el silencio del legislador no puede ser controlable por la jurisdicción constitucional - B. Segunda fórmula: el uso de las sentencias aditivas - C. Tercera fórmula: el exhorto al legislador - III. LA FÓRMULA DEL EXHORTO AL LEGISLADOR COMO SOLUCIÓN DE LAS OMISIONES INCONSTITUCIONALES EN EL CONTEXTO JURÍDICO COLOMBIANO - A. El escenario de los vacíos producidos como consecuencia de la declaratoria de inconstitucionalidad - B. El escenario de la modulación del efecto de los fallos en el tiempo - C. El escenario de las omisiones inconstitucionales relativas - D. El escenario de las omisiones inconstitucionales absolutas derivadas del texto de la Constitución - E. El escenario de las omisiones absolutas derivadas de la interpretación de la Constitución - IV. LAS ACTITUDES DE LA CORTE EN SUS EXHORTOS AL LEGISLADOR - A. La Corte prudente: el efecto retórico del exhorto - B. La Corte imperativa: aleccionando al Congreso - C. La Corte activista: ¿desafiando la esfera del legislador? - V. CONCLUSIONES - Referencias.

* Cómo citar este artículo: Celemín Caicedo, A. (Junio, 2016). El exhorto al legislador: análisis en la jurisprudencia de la Corte Constitucional colombiana. Revista de Derecho Público, (36). Universidad de los Andes (Colombia). DOI: http://dx.doi.org/10.15425/redepub.36.2016.04

** Abogada y magíster en Derecho de la Universidad Nacional de Colombia. Profesora de las cátedras Legislación y Políticas Públicas, Juez e Interpretación Constitucional, de la Facultad de Derecho de la Universidad de los Andes. Doctora en Derecho de la Universidad de los Andes. Correo: ya.celemin24@uniandes.edu.co 
Introducción

En un Estado constitucional, la idea de ramas separadas con funciones específicas y compartimentadas como garantía contra el ejercicio despótico del poder presupone la necesidad de definir con cierto nivel de exactitud el tipo de tareas que cada una debe desarrollar para establecer los límites, así como determinar los mecanismos de contrapeso y control que les permitan relacionarse entre sí. Por este motivo no resulta infrecuente la realización de descripciones en relación con las funciones de cada uno de los departamentos que conforman la estructura del Estado, de conformidad con las normas incluidas en las constituciones contemporáneas.

En relación con las funciones y actividades desempeñadas por el órgano legislativo, los interrogantes acerca del tipo de exigencias que le impone la Constitución se han descrito de manera canónica de la forma que se condensa en esta sencilla fórmula: es mandatorio para el Parlamento abstenerse de crear normas jurídicas contrarias al texto constitucional. Sin embargo, esta formulación ha comenzado a mostrarse insuficiente en la medida en que la idea de la supremacía de la Constitución y de la garantía de los derechos fundamentales en ella reconocidos empieza a ganar terreno como una limitación a la esfera de lo político.

Así, recientemente se ha construido una respuesta alterna, de acuerdo con la cual la supremacía de la Constitución le impone al legisla- dor más límites que los derivados de la clásica obligación de inhibirse de promulgar normas jurídicas contrarias a su texto. La posición de la Constitución como norma suprema, le exige al órgano legislativo la realización de conductas tendientes a desarrollar los postulados normativos necesarios para garantizar los derechos consagrados en ella. Sobre el particular sostiene Ferrajoli:

Pues bien, el conjunto de estas normas sustantivas, sean derechos primarios o derechos secundarios, circunscribe gracias a su constitucionalización, la que he llamado la esfera de lo indecidible: la esfera de lo "indecidible que", es decir, de lo que no está permitido o está prohibido decidir, determinada por el conjunto de los derechos individuales que excluyen, en cuanto expectativas negativas, decisiones que puedan dañarlos o reducirlos; y la esfera de lo "indecidible que no", es decir, de lo que no está permitido no (o es obligatorio) decidir, determinada por el conjunto de los derechos sociales en cuanto imponen expectativas positivas, decisiones idóneas para satisfacerlos. Solo lo que está por fuera de estos ámbitos es la esfera de lo decidible, dentro de la cual es legítimo el ejercicio de los derechos secundarios, instrumentales o de autonomía política, habitualmente mediada por la representación política, en la producción de las decisiones legislativas y de gobierno. (2011, p. 22).

Este complicado pero sustancioso extracto de la obra de Ferrajoli puede ser simplificado de 
la siguiente manera: en un Estado constitucional, lo decidible por el órgano legislativo es un espacio bastante más restringido de lo que desean aquellos que lo integran. Este espacio se describe como el resultado de sustraer un conjunto de decisiones que no pueden ser proferidas por este órgano por vulnerar o afectar los derechos fundamentales. $Y$ también, de adicionar un conjunto de normas que el legislador debe promulgar para la concretización de los derechos constitucionales.

En la actualidad existen mecanismos claros y bastante extendidos en las justicias constitucionales contemporáneas para corregir las trasgresiones del ámbito de lo "indecidible" efectuadas por el Parlamento. Así, cuando el legislador promulga una norma contraria a los derechos reconocidos en la Constitución, se ha conferido a los tribunales constitucionales una serie de competencias para invalidar la disposición mediante la cual se quebrantan estos límites, a través de la figura del control de constitucionalidad de las leyes. ${ }^{1}$

Pero los mecanismos con los que cuentan los tribunales constitucionales cuando detectan que el legislador omite expedir el conjunto de leyes necesarias para efectivizar los derechos consagrados en la Constitución no son ni fácil, ni pacíficamente determinables. En otros términos, la discusión actual no reporta respuestas unívocas o contundentes a la pregunta: ¿Cómo son controlables los silencios del legislador?

A pesar de que no existan respuestas unívocas para este interrogante el tribunal constitucional colombiano ha utilizado diversas fórmulas para el control de los silencios del legislador, cuando ellos se tornan en omisiones inconstitucionales.

\section{DESARROLLO DE LA REFLEXIÓN}

En el presente ensayo se efectúa una reflexión sobre la manera como se han controlado los silencios del legislador en la jurisprudencia de la Corte Constitucional colombiana. De acuerdo con este análisis, a pesar de que ninguna norma de la Constitución de 1991 determinó fórmulas para solucionar las omisiones legislativas inconstitucionales, la Corte Constitucional no se ha abstenido de identificar tales omisiones o de enviarle mensajes al legislador para que profiera las normas necesarias

1. A pesar de la amplitud del consenso en relación con las competencias de los tribunales constitucionales para el control constitucional de las leyes es preciso mencionar que existen fuertes reparos en relación con el alcance de estas competencias. Así, teóricamente existen posturas que respaldan el que los tribunales constitucionales cuenten con la potestad de declarar la inexequibilidad de una norma acusada como inconstitucional y retirarla del ordenamiento jurídico. Sin embargo, estas competencias están siendo objeto de discusión por algunos teóricos para quienes la única forma en la que el control constitucional es aceptable es en su versión débil. Autores como Jeremy Waldron describen este control judicial débil como la facultad del tribunal de detectar las razones por las cuales una norma es contraria a la Constitución, pero sin la posibilidad de retirar directamente del ordenamiento jurídico este tipo de normas. La idea del control débil de constitucionalidad solo autoriza al tribunal a devolver al órgano legislativo la norma vulneradora de la Constitución, para que sea este mismo órgano quien tome las decisiones necesarias para encuadrarla con el texto constitucional (Waldron, 2006, p. 1349). 
para solventarlas. Estos mensajes varían en su tono y van desde respetuosas y prudentes recomendaciones hasta invasiones a la órbita de competencias del órgano legislativo. Para sustentar esta tesis, el ensayo se divide en varias secciones. En la primera parte se determinará el concepto de silencio legislativo, sus diferencias con el concepto de omisión legislativa y las fórmulas determinadas para tratar esta clase de omisiones, mediante la descripción detallada de una de ellas: el exhorto al legislador. Más adelante se distinguirán los diversos escenarios en los que la Corte Constitucional ha utilizado las recetas creadas para el control de los silencios legislativos generadores de omisiones inconstitucionales, específicamente, mediante el uso de la figura del exhorto al legislador. En la última sección se analizarán los diversos tonos y actitudes usadas por la Corte cuando realiza estos exhortos. A partir de este análisis se intentará dilucidar hasta dónde las omisiones legislativas del legislador colombiano han sido sujetas a control por parte del Tribunal Constitucional, en su papel de garante de la supremacía de la Constitución.

\section{II. ¿CÓMO LIDIAR CON LOS SILENCIOS DEL LEGISLADOR CUANDO SE TORNAN EN OMISIONES INCONSTITUCIONALES?}

La teoría jurídica y la jurisprudencia han tenido la labor de decantar los mecanismos para lidiar con los silencios del legislador. Una primera manera de aproximarse a este concepto consiste en establecer la diferencia entre las expresiones silencio legislativo y omisión legis- lativa inconstitucional. Sobre el particular señala Ignacio Villaverde:

El legislador no es libre de decidir no legislar. Sin embargo, no todo silencio sobre el particular constituye un silencio contrario a la Constitución, es decir, una omisión inconstitucional. En mi opinión, solo aquellos silencios bien sea de la ley (silencios relativos, esto es, cuando una norma legal contiene omisiones), bien del legislador (silencios absolutos, que son aquellos en los que hay ausencia total de ley) que provoque [sic] situaciones jurídicas contrarias a la Constitución pueden y deben ser declarados omisiones inconstitucionales (2003, p. 50).

En otras palabras, no todo silencio legislativo es una omisión inconstitucional. La ocurrencia de la omisión se produce en aquellas oportunidades en las que por cuenta del silencio legislativo se generan situaciones concretas que vulneren o amenacen afectar los derechos constitucionales. Ahora bien, debe tenerse en cuenta que no todas las omisiones inconstitucionales son de la misma entidad. Una primera clasificación importante permite diferenciar entre las omisiones absolutas y las omisiones relativas.

En las omisiones absolutas existe una total carencia de regulación de una determinada situación que genera la violación de un derecho fundamental. Por su parte, en las omisiones relativas, la omisión no se presenta por la falta de actividad del legislador, sino más bien, por su actuación defectuosa o incompleta (Bulnes, 2006, p. 253). 
Una intervención adicional para la clarificación del manejo de las omisiones legislativas tiene que ver con la tipificación de las posibles respuestas que pueden construirse desde la doctrina, los tribunales o desde los textos constitucionales, para lidiar con los eventos en los que los silencios legislativos se convierten en verdaderas omisiones inconstitucionales. Así, se han identificado diversas fórmulas para dar tratamiento a las omisiones legislativas inconstitucionales.

\section{A. Primera fórmula: el silencio del legislador no puede ser controlable por la jurisdicción constitucional}

Una primera fórmula recomienda la abstención en los ordenamientos jurídicos de incluir recetas para controlar las omisiones legislativas mediante la intervención de los tribunales constitucionales. De acuerdo con esta postura, esta clase de intervenciones acarrea problemas sustanciales y procedimentales que redundan en afectaciones al principio democrático. Lo anterior, en la medida en que ellas acentúan el papel de las Cortes como los únicos órganos capacitados para defender la supremacía constitucional, en detrimento de los poderes del órgano parlamentario (Ruiz Miguel, 2004 p. 175). Tal y como se verá más adelante, esta recomendación teórica no ha tenido eco en el constitucionalismo colombiano.

\section{B. Segunda fórmula: el uso de las sentencias aditivas}

Una segunda fórmula utilizada a manera de remedio para solucionar las omisiones inconstitucionales, especialmente en los casos de las omisiones legislativas relativas, consiste en la posibilidad de que los tribunales constitucionales modulen sus fallos y perfeccionen la legislación incompleta, mediante el uso de las denominadas sentencias aditivas. ${ }^{2}$ En estas sentencias se transforma el significado de la ley que es controlada por el tribunal constitucional (Sarmiento, 2010, p. 234). Al apelar a este recurso las Cortes "manipulan" Ios enunciados normativos que llegan a su conocimiento, a través de los mecanismos de control abstracto de constitucionalidad. Aquellos apartes del texto normativo, en los que la ausencia de consideración por el legislador de alguna circunstancia relevante produce una omisión inconstitucional, son intervenidos por los tribunales constitucionales. Esta intervención se efectúa mediante la adición de los apartes textuales que resultan necesarios para situar a la disposición normativa acusada, en una posición de correspondencia con la Constitución.

\section{Tercera fórmula: el exhorto al legislador}

Un último recurso con el que cuentan los tribunales constitucionales para manejar los silencios

2. Ver, entre otras, las sentencias de la Corte Constitucional C-798/2008, J. Córdoba; C-109/1995, A. Martínez; y C-690/1996, A. Martínez. 
legislativos que producen las omisiones inconstitucionales es la utilización de una figura de corte intermedio entre las fórmulas anteriormente descritas: el exhorto al legislador. Mediante esta herramienta las Cortes ponen en conocimiento del Parlamento la existencia del vacío que produce situaciones contrarias a la Constitución, con la finalidad de que este órgano, dentro de su competencia, proceda a proferir las leyes necesarias para remediar la situación.

En términos más simples, el exhorto al legislador ha sido definido como una "recomendación sin coacción jurídica” (Bazán, 2003 p. 94), por cuanto se erige como una apelación o invitación al Parlamento para que aquel cumpla con su clásica función de creación legal, pero sin que se cuente con mecanismos claros para hacer un seguimiento a la forma como el órgano legislativo desempeña la tarea sugerida por el tribunal constitucional o para forzarlo a su cumplimiento.

A pesar de las discusiones teóricas existentes en relación con la efectividad de esta figura, algunos textos constitucionales han empezado a consagrar de forma explícita el uso del exhorto al legislador como un recurso válido y legítimo para remediar las omisiones legislativas:

Por otro lado, se encuentran los instrumentos normativizados específicamente para combatir la práctica de la negligencia legislativa. Por ejemplo se destacan la incorporación de normas constitucionales que imponen al legislador su deber constitucional de desarrollar la Constitución. La Constitución de la Ex
- Yugoslavia de 1974, (art. 377) en la Constitución portuguesa de 1976, (art. 279) y en su reforma de 1982 (art. 283), en la Constitución de Brasil de 1988 (art. 102.I y II), en la Constitución de la provincia de Río Negro en Argentina, en la Constitución de Costa Rica (art. 173 inciso f y artículo 75), en la Constitución de Hungría (Cláusula 32. A. 3) y más recientemente en la Constitución Bolivariana de Venezuela en su artículo 336.7. (Ramírez Cleves, 2006 p. 12).

Pero el derecho constitucional comparado ha mostrado que las peculiaridades en la redacción de estas cláusulas constitucionales producen diferencias relevantes en relación con los efectos de la figura del exhorto al legislador. Estas diferencias se mueven en un espectro amplio. Este espectro va desde un registro tímido en las actitudes de las Cortes, que se caracteriza por una retórica de coordinación y armonía en el desarrollo de las competencias estatales, hasta registros más fuertes. Recursos que inclusive son tolerantes con un cierto activismo de los tribunales constitucionales, en los que la retórica de la supremacía de la Constitución les impone a estos una cierta necesidad de reducir o solucionar la omisión inconstitucional de manera directa.

Sagüés (2007, pp. 256 a 259), por ejemplo, ha sistematizado las diversas formulaciones constitucionales para lidiar con las omisiones legislativas. De acuerdo con su sistematización, el catálogo de remedios para las omisiones legislativas va desde: (i) efectos prudentes (visibles en constituciones como la de Yugoslavia y la de 
Portugal) en las que el exhorto tiene tintes de mera sugerencia; hasta (ii) efectos más imperativos mediante la imposición de plazos a los órganos infractores de la Constitución como consecuencia de la omisión (como en el caso de la Constitución de Brasil); llegando a (iii) formulaciones mucho más despreocupadas por las libertades configurativas del legislador en materia de creación legal y en las que se tolera que los tribunales constitucionales se entrometan en la solución de la omisión inconstitucional. En estas formulaciones se faculta al tribunal constitucional para que de forma provisional y supletoria genere los lineamientos normativos necesarios para solucionar las omisiones inconstitucionales (como sería el caso de la Constitución venezolana) o también se autoriza la indemnización de las partes afectadas, como manera de responsabilizar al legislador por su indiferencia hacia la omisión (como sería el caso de la Constitución de la provincia de Río Negro en Argentina).

\section{LA FÓRMULA DEL EXHORTO AL LEGISLADOR COMO SOLUCIÓN DE LAS OMISIONES INCONSTITUCIONALES EN EL CONTEXTO JURÍDICO COLOMBIANO}

Se vio anteriormente que a nivel constitucional y doctrinal se identifican distintos mecanismos o fórmulas para dar tratamiento a las omisiones legislativas inconstitucionales y que una de ellas es el exhorto al legislador. Ahora bien, acerca del contexto jurídico colombiano se debe mencionar que la Constitución colombiana no incorporó, dentro del listado de innovaciones normati- vas para la defensa y garantía de los derechos constitucionales, la posibilidad de hacer uso del exhorto al legislador como una fórmula para manejar los silencios legislativos generadores de omisiones inconstitucionales. No obstante lo anterior, la Corte Constitucional colombiana desde los inicios de su actividad como guardiana de la integridad y la supremacía constitucional ha hecho reiterado uso de este recurso. En los próximos segmentos de este artículo se realizará una aproximación a la forma como se utiliza al exhorto al legislador en la doctrina constitucional producida por la Corte colombiana.

La ausencia de formulación constitucional del exhorto al legislador como un remedio para solucionar las omisiones legislativas inconstitucionales no ha sido óbice para que la Corte Constitucional, desde el año de 1994, haya usado esta figura. La primera reacción de la Corte colombiana en este sentido fue la de desarrollar el concepto de omisión legislativa como constructo teórico a partir del cual se profirieron sentencias exhortativas como mecanismo de control de los silencios del legislador. Sin embargo, sería una decisión de 2009, la Sentencia C-728/09, que se analizará más adelante, la que describió la utilización del exhorto en dos tipos de escenarios constitucionales en la jurisprudencia colombiana: (i) en los casos de las omisiones legislativas, y (ii) en los casos de modulación de los efectos en el tiempo de los fallos de la Corte Constitucional.

Ahora bien, un análisis del cúmulo de sentencias que la Corte Constitucional ha producido sobre este tema, desde el año de 1994 hasta 
la fecha, incluida la Sentencia C-728 de 2009, permite construir una tipología más extensa y generosa que la ofrecida por la Corte en esta decisión constitucional. A continuación se detallan con mayor profundidad los escenarios en los que la Corte colombiana ha hecho uso de la figura del exhorto, como consecuencia de la detección de una omisión inconstitucional.

\section{A. El escenario de los vacíos producidos como consecuencia de la declaratoria de inconstitucionalidad}

En este escenario, más que la inexistencia de una norma por negligencia, inactividad o inde- cisión legislativa, la remoción de una norma del sistema jurídico causada por el despliegue de la actividad de control abstracto de constitucionalidad de la Corte, produce un vacío en el ordenamiento que puede llegar a afectar derechos fundamentales. Como mecanismo de protección de los derechos, la Corte ha usado el exhorto al legislador y ha puesto en conocimiento del órgano legislativo la manera como la mencionada declaratoria de inconstitucionalidad afectó la completitud del ordenamiento jurídico. El objetivo de este aviso es lograr que el órgano legislativo produzca las normas jurídicas correspondientes. Un ejemplo de esta clase de exhorto se presenta en la tabla 1.

Tabla 1. Exhorto sobre muerte digna planteado por la Corte en la Sentencia C-239/1997

\begin{tabular}{|c|c|c|c|}
\hline Sentencia & $\begin{array}{c}\text { Contextualización } \\
\text { del caso }\end{array}$ & $\begin{array}{c}\text { Derecho } \\
\text { constitucional } \\
\text { en riesgo }\end{array}$ & $\begin{array}{c}\text { Observaciones sobre los } \\
\text { términos del exhorto } \\
\text { utilizados por la Corte }\end{array}$ \\
1997 & $\begin{array}{c}\text { Se demandó la constitucionali- } \\
\text { dad de las normas del Código } \\
\text { Penal de la época que sancio- } \\
\text { naban el homicidio por piedad, } \\
\text { por considerar el demandante } \\
\text { que las penas incluidas en la } \\
\text { norma eran demasiado leves, } \\
\text { y que desprotegían el derecho } \\
\text { a la vida. La Corte profirió una } \\
\text { sentencia modulativa para so- } \\
\text { lucionar el caso. De un lado } \\
\text { declaró la constitucionalidad } \\
\text { de las normas y de la pena } \\
\text { establecida en ellas, por con- }\end{array}$ & $\begin{array}{l}\text { Dignidad humana } \\
\text { y autonomía perso- } \\
\text { nal. }\end{array}$ & $\begin{array}{l}\text { Sobre el exhorto realizado por } \\
\text { la Corte en esta decisión es } \\
\text { necesario precisar un aspecto } \\
\text { importante. En el cuerpo de la } \\
\text { sentencia el alto tribunal esta- } \\
\text { bleció una serie de elementos } \\
\text { mínimos necesarios que debe- } \\
\text { ría contener la regulación de la } \\
\text { eutanasia, a ser expedida por } \\
\text { el Congreso de la República de } \\
\text { Colombia. En otros términos, } \\
\text { la Corte tuvo un rol más cola- } \\
\text { borativo con el legislador, al } \\
\text { exponerle algunos elementos }\end{array}$ \\
\hline
\end{tabular}




\begin{tabular}{|c|c|c|c|}
\hline Sentencia & $\begin{array}{c}\text { Contextualización } \\
\text { del caso }\end{array}$ & $\begin{array}{c}\text { Derecho } \\
\text { constitucional } \\
\text { en riesgo }\end{array}$ & $\begin{array}{c}\text { Observaciones sobre los } \\
\text { términos del exhorto } \\
\text { utilizados por la Corte }\end{array}$ \\
\hline & $\begin{array}{l}\text { siderar que la disminución de } \\
\text { la pena resultaba proporciona- } \\
\text { da y razonable. Pero, simultá- } \\
\text { neamente, declaró la incons- } \\
\text { titucionalidad de las normas } \\
\text { demandadas, en los casos en } \\
\text { los que el homicidio por piedad } \\
\text { fuera realizado para terminar } \\
\text { el dolor de enfermos termina- } \\
\text { les, siempre y cuando concu- } \\
\text { rriera la voluntad libre del su- } \\
\text { jeto pasivo del acto. La Corte } \\
\text { determinó que para proteger el } \\
\text { principio de dignidad humana } \\
\text { no era posible derivar respon- } \\
\text { sabilidad penal para el médi- } \\
\text { co autor, pues la conducta en } \\
\text { estos casos estaría justificada } \\
\text { y por ende no se incurriría en } \\
\text { homicidio por piedad. }\end{array}$ & & $\begin{array}{l}\text { importantes a considerar en el } \\
\text { momento de solucionar la omi- } \\
\text { sión legislativa. }\end{array}$ \\
\hline
\end{tabular}

Fuente: elaboración propia con base en la sentencia C-239/1997.

\section{B. El escenario de la modulación del efecto de los fallos en el tiempo}

Un segundo escenario en el que la Corte ha apelado al uso de la figura del exhorto al legislador es el relacionado con la modulación de los efectos de sus fallos en el tiempo. En este escenario, la Corte se enfrenta a omisiones legislativas relativas que al ser confrontadas con el texto constitucional producen la vulneración de la norma suprema. Sin embargo, en ciertas oportunidades la Corte ha puesto de manifiesto que la declaración inmediata de inconstitucionalidad de la medida legislativa en la que se detectó la omisión produciría consecuencias adversas para el orden jurídico, económico o social del país. En estas circunstancias, la Corte realiza una modulación de los efectos de sus fallos en el tiempo y determina, en el decisum, la fecha a partir de la cual la declaratoria de inconstitucionalidad cobrará vigencia. Pero como medida paralela para ga- 
rantizar la eficacia de su decisión recurre al exhorto al legislador, pues de lo contrario no sería posible solucionar la omisión una vez se cumpla el plazo determinado para la pérdida de validez jurídica de la norma declarada como inconstitucional. En este tipo de exhortos resulta entonces característico la imposición de un plazo, que se corresponde con el término en el que se difiere la declaración de inconstitucionalidad, para que el órgano legislativo promueva la nueva normativa que remplazará a la señalada como infractora del régimen constitucional. Ejemplo de este escenario se presenta en la tabla 2.

Tabla 2. Exhorto sobre el Código de Minas planteado por la Corte en la Sentencia C-366/2011

\begin{tabular}{|c|c|c|c|}
\hline Sentencia & $\begin{array}{c}\text { Contextualización } \\
\text { del caso }\end{array}$ & $\begin{array}{c}\text { Norma } \\
\text { constitucional } \\
\text { afectada }\end{array}$ & $\begin{array}{l}\text { Observaciones sobre } \\
\text { los términos del exhorto } \\
\text { utilizados por la Corte }\end{array}$ \\
\hline $\begin{array}{c}\text { C-366 } \\
\text { de } 2011\end{array}$ & $\begin{array}{l}\text { Se demandó la inconstitucio- } \\
\text { nalidad de una ley que modi- } \\
\text { ficaba el Código de Minas por } \\
\text { haber sido promulgada sin la } \\
\text { realización de consulta previa. } \\
\text { La consulta previa es una me- } \\
\text { dida necesaria para garantizar } \\
\text { los derechos de participación } \\
\text { de los pueblos indígenas y } \\
\text { otras minorías étnicas en las } \\
\text { decisiones que los afectan. En } \\
\text { este caso concreto, decisiones } \\
\text { e intervenciones específica- } \\
\text { mente relacionadas con la ex- } \\
\text { plotación minera dentro de sus } \\
\text { territorios. La Corte determinó } \\
\text { que el Código de Minas era una } \\
\text { medida legislativa que afecta- } \\
\text { ba directamente la explotación } \\
\text { de los territorios ancestrales de } \\
\text { las minorías étnicas del país y } \\
\text { constató que efectivamente se } \\
\text { había promulgado sin la rea- } \\
\text { lización de la consulta previa. }\end{array}$ & $\begin{array}{l}\text { Diversidad étnica } \\
\text { y cultural de las } \\
\text { comunidades indí- } \\
\text { genas y otras mi- } \\
\text { norías étnicas de la } \\
\text { nación colombiana. }\end{array}$ & $\begin{array}{l}\text { En este caso, la Corte detectó la } \\
\text { omisión del legislador que afec- } \\
\text { tó los derechos de las minorías } \\
\text { étnicas a ser consultadas so- } \\
\text { bre las decisiones relacionadas } \\
\text { con la explotación de sus terri- } \\
\text { torios por actividades mineras. } \\
\text { Sin embargo, el alto tribunal } \\
\text { consideró como inadecuada la } \\
\text { solución de declarar de forma } \\
\text { inmediata la inconstitucionali- } \\
\text { dad de la decisión, una vez de- } \\
\text { tectó la omisión legislativa in- } \\
\text { constitucional. Por este motivo } \\
\text { moduló los efectos de su fallo } \\
\text { en el tiempo, para darle al le- } \\
\text { gislador tiempo y espacio para } \\
\text { proferir una nuevo Código, en } \\
\text { el que este órgano no omitiera } \\
\text { su deber de efectuar la consul- } \\
\text { ta previa a los miembros de las } \\
\text { minorías étnicas. A la fecha el } \\
\text { Congreso no ha expedido esta } \\
\text { regulación. }\end{array}$ \\
\hline
\end{tabular}




\begin{tabular}{|c|l|c|c|}
\hline Sentencia & \multicolumn{1}{c|}{$\begin{array}{c}\text { Contextualización } \\
\text { del caso }\end{array}$} & $\begin{array}{c}\text { Norma } \\
\text { constitucional } \\
\text { afectada }\end{array}$ & $\begin{array}{c}\text { Observaciones sobre } \\
\text { los términos del exhorto } \\
\text { utilizados por la Corte }\end{array}$ \\
\hline $\begin{array}{l}\text { Con base en estas considera- } \\
\text { ciones, la Corte declaró la in- } \\
\text { constitucionalidad de la ley de- } \\
\text { mandada. Sin embargo, profirió } \\
\text { una sentencia modulativa difi- } \\
\text { riendo los efectos de la decla- } \\
\text { ratoria de inconstitucionalidad } \\
\text { en el tiempo, por un término de } \\
\text { dos años. }\end{array}$ & \\
\hline
\end{tabular}

Fuente: elaboración propia con base en la sentencia C-366/2011.

\section{El escenario de las omisiones inconstitucionales relativas}

Probablemente, este es el escenario en el que la Corte colombiana ha acudido de forma más frecuente al uso de la figura del exhorto al legislador. Para comprenderlo resulta preciso definir con mayor detalle las omisiones inconstitucionales relativas:

En estos casos hay un enunciado legal que regula una determinada situación jurídica, pero lo hace defectuosamente, omitiendo en su regulación alguna de sus dimensiones. Olvido que puede acarrear la inconstitucionalidad de esa norma legal. En estos supuestos, no existe propiamente laguna, aunque sí un vacío normativo, y, además, varía el control de constitucionalidad. En efecto, en los silencios de la ley lo que es objeto de control es la norma legal explícita, aunque el motivo de su impugnación no sea su texto (precepto), sino justamente lo que no dice su texto: la norma jurídica que de su silencio quepa derivar (Villaverde, 2003, p. 81).

Esta clase de omisiones son fácilmente identificables en la actividad de la Corte cuando da respuesta a demandas ciudadanas contra normas de carácter sancionatorio como las contenidas en el Código Penal o en el Estatuto Tributario, entre otras. Por ejemplo, los demandantes de estos procesos acusan la manera como los defectos en la redacción de determinados tipos penales afectan el principio de tipicidad o legalidad. Para estos casos, la Corte actúa retirando del ordenamiento el tipo defectuosamente configurado y exhortando al Congreso para que proceda a expedir una nueva norma mucho más respetuosa de los principios que rigen el derecho sancionatorio. Una de las sentencias en las que se ha apelado al exhorto como mecanismo de solución de las omisiones inconstitucionales relativas es la que se examina en la tabla 3. 
Tabla 3. Exhorto sobre el Código de la Infancia y la Adolescencia planteado por la Corte en la Sentencia C-684/2009

\begin{tabular}{|c|c|c|c|}
\hline Sentencia & $\begin{array}{c}\text { Contextualización } \\
\text { del caso }\end{array}$ & $\begin{array}{l}\text { Derecho } \\
\text { constitucional } \\
\text { en riesgo }\end{array}$ & $\begin{array}{l}\text { Observaciones sobre } \\
\text { los términos del exhorto } \\
\text { utilizados por la Corte }\end{array}$ \\
\hline $\begin{array}{c}\text { C-684 } \\
\text { de } 2009\end{array}$ & $\begin{array}{l}\text { Se demandó una norma del } \\
\text { Código de la Infancia y la Ado- } \\
\text { lescencia que permitía la cap- } \\
\text { tura en flagrancia de menores } \\
\text { infractores. La demanda se } \\
\text { fundamentó en la existencia } \\
\text { de una omisión relativa de la } \\
\text { norma acusada. Lo anterior por } \\
\text { cuanto el legislador no tuvo en } \\
\text { cuenta ciertas etapas de esta } \\
\text { clase de procesos que sí se es- } \\
\text { tablecen en los procesos para } \\
\text { infractores mayores de edad. } \\
\text { La Corte declaró la inconstitu- } \\
\text { cionalidad de la norma deman- } \\
\text { dada al considerar que a pesar } \\
\text { de que el Código de la Infancia } \\
\text { y la Adolescencia establecía la } \\
\text { necesidad de diferenciar entre } \\
\text { los procedimientos para me- } \\
\text { nores infractores y los adultos, } \\
\text { la diferenciación efectuada en } \\
\text { la norma demandada no re- } \\
\text { sultaba respetuosa del debido } \\
\text { proceso de los menores infrac- } \\
\text { tores. Ello en razón a que la } \\
\text { norma demandada era dema- } \\
\text { siado indeterminada. Pero esta } \\
\text { indeterminación no necesaria- } \\
\text { mente conducía a proteger los } \\
\text { intereses superiores del me- } \\
\text { nor, al permitir un cierto grado } \\
\text { de discrecionalidad de los ope- } \\
\text { radores jurídicos que adelan- }\end{array}$ & $\begin{array}{l}\text { Debido proceso en } \\
\text { materia penal. }\end{array}$ & $\begin{array}{l}\text { En esta decisión la Corte com- } \\
\text { bina la técnica de exhorto con } \\
\text { la expedición de una senten- } \\
\text { cia aditiva en la que ella mis- } \\
\text { ma completa el vacío que se } \\
\text { genera por la declaración de } \\
\text { inconstitucionalidad de la nor- } \\
\text { ma contentiva de la omisión } \\
\text { relativa. Por ello, la Corte da la } \\
\text { orden de que esta clase de pro- } \\
\text { cesos se adelante siguiendo } \\
\text { las preceptivas del Código de } \\
\text { Procedimiento Penal. Al mismo } \\
\text { tiempo, efectúa el exhorto para } \\
\text { que el Parlamento colombiano } \\
\text { expida una nueva normatividad } \\
\text { plenamente garantista de los } \\
\text { principios del debido proceso } \\
\text { en materia penal. }\end{array}$ \\
\hline
\end{tabular}




\begin{tabular}{|l|l|l|l|}
\hline Sentencia & \multicolumn{1}{|c|}{$\begin{array}{c}\text { Contextualización } \\
\text { del caso }\end{array}$} & $\begin{array}{c}\text { Derecho } \\
\text { constitucional } \\
\text { en riesgo }\end{array}$ & $\begin{array}{c}\text { Observaciones sobre } \\
\text { los términos del exhorto } \\
\text { utilizados por la Corte }\end{array}$ \\
\hline $\begin{array}{l}\text { tan el proceso, sino que podría } \\
\text { llegar a lesionar el debido pro- } \\
\text { ceso de los sujetos activos de } \\
\text { la infracción penal. Con base } \\
\text { en la declaratoria de inexequi- } \\
\text { bilidad, la Corte ordenó que } \\
\text { estos procesos se adelantaran } \\
\text { siguiendo el Código de Procedi- } \\
\text { miento Penal. }\end{array}$ & \\
\hline
\end{tabular}

Fuente: elaboración propia con base en la sentencia C-684/2009.

\section{El escenario de las omisiones inconstitucionales absolutas derivadas del texto de la Constitución}

Otro tipo de omisiones inconstitucionales que han sido de conocimiento de la Corte Constitucional colombiana y para cuya solución ha hecho uso del exhorto al legislador es el de las omisiones absolutas derivadas del texto de la Constitución. Este tipo de omisiones se producen por la desatención del legislador a un imperativo expresamente consagrado en alguna norma en la que la Carta política le confirió el deber de desarrollar algún principio o postulado constitucional. Sobre esta clase de omisiones legislativas ha comentado la doctrina:

La presencia de un encargo al legislador para que produzca una omisión inconstitu- cional es esencial porque una omisión tendrá relevancia jurídica solo cuando exista un precepto jurídico que establezca una conducta y precisamente dicha omisión lesione tal concepto. La omisión pasa así, como señala Sthaler de un "no hacer nada" a un "no hacer algo", siendo este algo lo que espera el orden jurídico. No se fundamenta en la no realización de una acción arbitraria, sino en la no realización de una esperada, debida, de manera que el centro de toda discusión acerca de la omisión del legislador es el encargo constitucional que resulta vinculante. (Fernández, 2003, p. 20).

Como ejemplo de este escenario de utilización de la figura del exhorto al legislador puede señalarse el caso que se presenta en la tabla 4. 
Tabla 4. Exhorto para la determinación de los servicios públicos esenciales planteado por la Corte en la Sentencia C-473/1994.

\begin{tabular}{|c|c|c|c|}
\hline Sentencia & $\begin{array}{c}\text { Contextualización } \\
\text { del caso }\end{array}$ & $\begin{array}{l}\text { Derecho } \\
\text { constitucional } \\
\text { en riesgo }\end{array}$ & $\begin{array}{l}\text { Observaciones sobre } \\
\text { los términos del exhorto } \\
\text { utilizados por la Corte }\end{array}$ \\
\hline $\begin{array}{c}\text { C-473 } \\
\text { de } 1994\end{array}$ & $\begin{array}{l}\text { Se demandó la inconstitucio- } \\
\text { nalidad de ciertas normas del } \\
\text { Código Sustantivo del Trabajo } \\
\text { relativas a la prohibición de } \\
\text { la huelga en servicios públi- } \\
\text { cos por contrariar el criterio } \\
\text { del artículo } 56 \text { de la Consti- } \\
\text { tución Política (CP). En esta } \\
\text { norma constitucional se hace } \\
\text { alusión a la prohibición de la } \\
\text { huelga en los servicios públi- } \\
\text { cos esenciales y se promulga } \\
\text { el deber del legislador de defi- } \\
\text { nir este concepto y de regular } \\
\text { este derecho. La Corte profirió } \\
\text { una decisión modulativa en la } \\
\text { que declaró la constituciona- } \\
\text { lidad de la interpretación del } \\
\text { enunciado normativo que pro- } \\
\text { híbe la huelga para los servi- } \\
\text { cios públicos esenciales y la } \\
\text { inconstitucionalidad de una } \\
\text { interpretación del enunciado } \\
\text { normativo a partir del cual se } \\
\text { podría prohibir el ejercicio de } \\
\text { la huelga para cualquier tipo } \\
\text { de servicio público, sin distin- } \\
\text { guir su carácter. }\end{array}$ & Derecho de huelga. & $\begin{array}{l}\text { Este fallo es fundador de una } \\
\text { línea jurisprudencial en la que } \\
\text { la Corte Constitucional ha con- } \\
\text { tinuado reiterando este exhorto } \\
\text { para que el Parlamento colom- } \\
\text { biano expida la regulación en } \\
\text { materia de servicios públicos } \\
\text { esenciales, pues hasta la fecha } \\
\text { y después de más de veinte } \\
\text { años de expedición de la Cons- } \\
\text { titución de } 1991 \text { el Congreso } \\
\text { no ha definido el concepto de } \\
\text { servicio público esencial en el } \\
\text { ordenamiento jurídico colom- } \\
\text { biano. Hacen parte de esta } \\
\text { línea las sentencias T-812 de } \\
2012 \text {, T-171 de } 2011 \text { y C-095 } \\
\text { de } 1997 \text {. }\end{array}$ \\
\hline
\end{tabular}

Fuente: elaboración propia con base en la sentencia C-473/1994. 


\section{E. El escenario de las omisiones absolutas derivadas de la interpreta- ción de la Constitución}

En este escenario la actividad interpretativa de la Corte determina la existencia de la omisión inconstitucional, pues del texto expreso de la norma no se colige el deber del legislador de desarrollar un determinado mandato constitucional para hacerlo efectivo. La característica de este escenario es su surgimiento tardío en la jurisprudencia de la Corte Constitucional (a partir de 2009). En otras palabras, se trata de sentencias recientes, directamente conectadas con líneas jurisprudenciales relacionadas con derechos fundamentales específicos como el derecho a la objeción de conciencia para la prestación del servicio militar y los derechos de las parejas del mismo sexo.

La solución a los problemas jurídicos concretos que surgen por la afectación de esta clase de derechos no fue pacífica, coherente o unidireccional en la jurisprudencia nacional. Por el contrario, requirió que la Corte previamente decantara y estabilizara su propia postura frente a estas situaciones particulares. Este fenómeno explica el uso del exhorto como un paso posterior y tardío para esta clase de escenarios constitucionales. La apelación al exhorto pretende que el órgano legislativo produzca las normas jurídicas necesarias para garantizar el pleno goce de estos derechos, de acuerdo con la forma como a través de la jurisprudencia ellos se han venido re- conociendo por la Corte colombiana. Sobre la existencia de mecanismos de control constitucional en esta clase de escenarios comenta la doctrina:

En realidad, en estos casos se identifique o no el silencio legislativo con una laguna jurídica, lo cierto es que tras la inconstitucionalidad por omisión absoluta no se esconde más que una interpretación judicial de una norma jurídica respecto de la que no hay norma legal alguna específica sobre la materia, incluso es posible que no haya norma alguna sobre el particular, y sin embargo, deba fijar la regla concreta que las rija. De este modo tras los silencios del legislador, no hay más que un problema de interpretación-integración judicial del ordenamiento jurídico. (Villaverde, 2003 p. 80).

Como ejemplos de ese escenario se traen a colación las sentencias de la jurisprudencia coIombiana que se presentan en la tabla 5.

En esta sección se han descrito los distintos escenarios en los que la Corte Constitucional ha apelado a la figura del exhorto al legislador como fórmula para dar solución a las omisiones legislativas detectadas en el ordenamiento jurídico colombiano. Sin embargo, es de señalar que no ha asumido el mismo tono en todos ellos, situación que se analiza en la siguiente sección junto con los mecanismos utilizados por dicho organismo cuando ha proferido exhortos al legislador como un instrumento para solucionar las omisiones detectadas. 
Tabla 5. Exhortos derivados de la interpretación

\begin{tabular}{|c|c|c|c|}
\hline Sentencia & $\begin{array}{c}\text { Contextualización } \\
\text { del caso }\end{array}$ & $\begin{array}{l}\text { Derecho } \\
\text { constitucional } \\
\text { en riesgo }\end{array}$ & $\begin{array}{l}\text { Observaciones sobre } \\
\text { los términos del exhorto } \\
\text { utilizados por la Corte }\end{array}$ \\
\hline $\begin{array}{l}\text { C-577 } \\
\text { de } 2011\end{array}$ & $\begin{array}{l}\text { Se demandó la constituciona- } \\
\text { lidad de ciertas normas de la } \\
\text { legislación de familia que de- } \\
\text { finín el matrimonio sin tomar } \\
\text { en consideración la posibilidad } \\
\text { de que parejas del mismo sexo } \\
\text { puedan contraerlo, por estable- } \\
\text { cer que se trata de contratos } \\
\text { solemnes entre un hombre y } \\
\text { una mujer. De acuerdo con los } \\
\text { argumentos esgrimidos en esta } \\
\text { demanda, la no inclusión del } \\
\text { matrimonio de las parejas del } \\
\text { mismo sexo afecta el derecho } \\
\text { a la igualdad y al libre desarro- } \\
\text { llo de la personalidad. La Corte } \\
\text { declaró la constitucionalidad } \\
\text { de la norma demandada pero } \\
\text { al constatar que existe un "dé- } \\
\text { ficit de protección" de los dere- } \\
\text { chos de las parejas del mismo } \\
\text { sexo, determinó la necesidad } \\
\text { de exhortar al Congreso para } \\
\text { que regule la materia. }\end{array}$ & $\begin{array}{l}\text { Derecho a la igual- } \\
\text { dad de las parejas } \\
\text { del mismo sexo. }\end{array}$ & $\begin{array}{l}\text { En este caso, la Corte combina } \\
\text { varias técnicas para intentar } \\
\text { dar solución a la omisión legis- } \\
\text { lativa. En primer lugar, estable- } \\
\text { ció un plazo -hasta junio de } \\
2013-\text { para que el legislador } \\
\text { profiriera las normas que regu- } \\
\text { laran en el ordenamiento jurí- } \\
\text { dico colombiano el matrimonio } \\
\text { de parejas del mismo sexo. Sin } \\
\text { embargo, y de forma adicional, } \\
\text { impuso una consecuencia para } \\
\text { efectivizar el exhorto: si el legis- } \\
\text { lador no profiere la normativa } \\
\text { necesaria para solucionar la } \\
\text { omisión legislativa en relación } \\
\text { con los derechos de las pare- } \\
\text { jas del mismo sexo, los afecta- } \\
\text { dos pueden acudir a las auto- } \\
\text { ridades públicas para contraer } \\
\text { matrimonio. Con esta segunda } \\
\text { formulación, la Corte determi- } \\
\text { nó que cuando las autoridades } \\
\text { competentes se nieguen a rea- } \\
\text { lizar esta clase de matrimonios, } \\
\text { la jurisdicción constitucional } \\
\text { mediante acciones jurisdiccio- } \\
\text { nales de control concreto de } \\
\text { constitucionalidad puede prote- } \\
\text { ger los derechos de las perso- } \\
\text { nas en estas circunstancias. }\end{array}$ \\
\hline $\begin{array}{l}\text { C-728 } \\
\text { de } 2009\end{array}$ & $\begin{array}{l}\text { Se demandó la constitucionali- } \\
\text { dad de una norma relacionada }\end{array}$ & $\begin{array}{l}\text { Libertad de con- } \\
\text { ciencia y de cultos. }\end{array}$ & $\begin{array}{l}\text { En este caso concreto la Corte } \\
\text { no profirió una sentencia aditi- }\end{array}$ \\
\hline
\end{tabular}




\begin{tabular}{|c|c|c|c|}
\hline Sentencia & $\begin{array}{c}\text { Contextualización } \\
\text { del caso }\end{array}$ & $\begin{array}{c}\text { Derecho } \\
\text { constitucional } \\
\text { en riesgo }\end{array}$ & $\begin{array}{c}\text { Observaciones sobre } \\
\text { los términos del exhorto } \\
\text { utilizados por la Corte }\end{array}$ \\
\hline & $\begin{array}{l}\text { con el régimen de exenciones } \\
\text { en todo tiempo para la presta- } \\
\text { ción del servicio militar obliga- } \\
\text { torio, en la que se incluyó: (i) a } \\
\text { los limitados físicos y sensoria- } \\
\text { les, y (ii) a los miembros de las } \\
\text { comunidades indígenas que } \\
\text { residan en su territorio, pero } \\
\text { se omitió incluir a los objetores } \\
\text { de conciencia. De acuerdo con } \\
\text { la demanda, esta abstención } \\
\text { constituía una omisión relativa } \\
\text { inconstitucional por afectar la } \\
\text { libertad de conciencia estable- } \\
\text { cida en el artículo } 18 \text { de la CPy } \\
\text { la libertad de cultos consagra- } \\
\text { da en el artículo } 19 \text { de la CP. La } \\
\text { Corte declaró la exequibilidad } \\
\text { de la norma demandada; sin } \\
\text { embargo modificó gradualmen- } \\
\text { te su postura por considerar } \\
\text { que en decisiones previas ha- } \\
\text { bía determinado que la Consti- } \\
\text { tución no reconocia la objeción } \\
\text { de conciencia y, por tanto, este } \\
\text { derecho no podía ser ejercita- } \\
\text { do. Esta modificación obligaba } \\
\text { a rectificar las subreglas consti- } \\
\text { tucionales sobre la materia. En } \\
\text { este sentido, la Corte reconoció } \\
\text { que este cambio inició con la } \\
\text { aceptación del ejercicio de esta } \\
\text { figura en contextos distintos al } \\
\text { de la prestación del servicio }\end{array}$ & & $\begin{array}{l}\text { va, ni le impuso un plazo al Con- } \\
\text { greso para la expedición de la } \\
\text { reglamentación necesaria para } \\
\text { solucionar la omisión legisla- } \\
\text { tiva. Sin embargo, la decisión } \\
\text { resulta de interés por cuanto } \\
\text { la Corte determinó que las per- } \\
\text { sonas afectadas por esta au- } \\
\text { sencia de regulación estaban } \\
\text { legitimadas para incoar meca- } \\
\text { nismos de control concreto de } \\
\text { constitucionalidad, como la ac- } \\
\text { ción de tutela para garantizar } \\
\text { el ejercicio de este derecho. En } \\
\text { la actualidad, en el Congreso } \\
\text { se está tramitando un proyecto } \\
\text { de ley estatutaria (N. }{ }^{\circ} 20 \text { de } \\
2015 \text { Senado) para solucionar } \\
\text { la omisión legislativa. }\end{array}$ \\
\hline
\end{tabular}




\begin{tabular}{|l|l|c|c|}
\hline Sentencia & \multicolumn{1}{c|}{$\begin{array}{c}\text { Contextualización } \\
\text { del caso }\end{array}$} & $\begin{array}{c}\text { Derecho } \\
\text { constitucional } \\
\text { en riesgo }\end{array}$ & $\begin{array}{c}\text { Observaciones sobre } \\
\text { los términos del exhorto } \\
\text { utilizados por la Corte }\end{array}$ \\
\hline $\begin{array}{l}\text { rio cambiar la jurisprudencia } \\
\text { y permitir la invocación de la } \\
\text { objeción de conciencia para la } \\
\text { prestación del servicio militar. } \\
\text { Sostuvo, además, que la obje- } \\
\text { ción de conciencia no puede } \\
\text { comprenderse como una omi- } \\
\text { sión de la ley que se abstuvo } \\
\text { de regular la figura en el artícu- } \\
\text { lo demandado, tal y como lo ar- } \\
\text { gumentó la demanda, sino que } \\
\text { se trata de una omisión legis- } \\
\text { lativa absoluta. Por este motivo } \\
\text { acudió al exhorto y, de forma } \\
\text { adicional, señaló que mientras } \\
\text { se expide la regulación sobre la } \\
\text { materia, la Constitución puede } \\
\text { aplicarse directamente para } \\
\text { la protección de la libertad de } \\
\text { conciencia mediante el uso de } \\
\text { la acción de tutela. }\end{array}$ & & \\
\end{tabular}

Fuente: elaboración propia con base en las sentencias C-577/2011 y C-728/2009.

\section{LAS ACTITUDES DE LA CORTE EN SUS EXHORTOS AL LEGISLADOR \\ A. La Corte prudente: el efecto retórico del exhorto}

La mayoría de las veces en las que la Corte Constitucional colombiana ha acudido a la figura del exhorto al legislador ha usado un tono discreto y prudente al poner en conocimiento la omisión legislativa, sin extender sus consideraciones a los efectos que esta produce respecto a la eficacia de la Constitución. En estas ocasiones se abstiene de elaborar un discurso imperativo en el que cuestione los límites a la esfera de lo político que la idea de la supremacía de la Constitución le impone al Parlamento, y más bien se dirige tímidamente al legislador 
en los apartes finales de la decisión, actuando como lo haría un verdadero consejero. ${ }^{3}$

En otras oportunidades acompaña su recomendación con reflexiones acerca del profundo respeto por el principio de la separación de poderes y por la necesidad de que las ramas del poder público se relacionen de manera armónica, pero sin invadir las órbitas de sus correspondientes competencias, como argumentos que justifican la apelación al exhorto.

A manera de ejemplo se incluye la decisión en la que la Corte mostró su "prudencia" al proferir el exhorto mediante la elaboración de un discurso en el que sacó a relucir las credenciales democráticas del legislador como cartas de garantía suficientes para la protección de los derechos constitucionales. Sobre el particular resultan interesantes los siguientes extractos:

Es importante insistir en que la decisión de reconocer esos derechos a las parejas del mismo sexo no debería ser labor del juez constitucional, porque el escenario natural y propicio para ese efecto es el Congreso de la República, en donde hay un sustrato de representación democrática, pues allí tienen asiento los distintos grupos que conforman nuestra sociedad, elegidos por la voluntad popular y que permite una deliberación amplia y prolija sobre un asunto tan trascendental como el de los derechos de las parejas del mismo sexo, representación democráti- ca que presenta un déficit en tratándose de esta Corporación, porque si bien sus miembros son electos por el Senado de la República de sendas ternas que conforman el Presidente de la República, el Consejo de Estado y la Corte Suprema de Justicia, no puede compararse con la que tiene el Congreso de la República ni mucho menos con su función deliberativa.

(...)

En este mismo sentido, Jeremy Waldron considera que cuando la comunidad política está dividida acerca de cuáles son los derechos morales de los que son titulares los individuos, cómo hay que interpretarlos, y cómo deben conciliarse sus exigencias contrapuestas, es inevitable que esa comunidad recurra a algún procedimiento para zanjar los efectos prácticos de esa controversia. El procedimiento más recomendable desde el punto de vista de una teoría liberal que propugne los valores de la autonomía y la igualdad de las personas, es el procedimiento democrático, en cabeza del Parlamento. Un procedimiento en el que todos los ciudadanos participan con su voz y con su voto, bien directamente, bien a través de representantes, y en el que se decide por mayoría.

Por tanto, se impone que el legislador asuma su función constitucional, y con la participación de toda la sociedad debata y defina asuntos axiales a estas relaciones como, por

3. Ver, entre otras, la Sentencia C-699/2007, R. Escobar. 
ejemplo, la forma jurídica que puede tener su vínculo y los derechos que de él se pueden derivar. (CConst., C-283/2011, J. Pretelt). ${ }^{4}$

Estos extractos muestran una Corte demasiado respetuosa de las libertades configurativas del legislador y hasta confiada en que el Parlamento es el escenario privilegiado o, por qué no, "natural", para solventar las discusiones y los desacuerdos más agudos en los que se fundamentan los problemas irresueltos de las sociedades contemporáneas.

\section{B. La Corte imperativa: aleccionando al Congreso}

Pero la Corte no solo actúa de forma tímida y prudente. En otras ocasiones es posible notar a un tribunal más impositivo, que ya no solo aconseja sino que también advierte. Esta actitud se evidencia en la imposición de mecanismos que, como los plazos, parecen cohibir en una mayor medida el ejercicio configurativo del legislador. También, mediante la aportación de algunas ideas que pueden ser útiles para el legislador en la solución de la omisión inconstitucional detectada. Un ejemplo de esta clase de actitud se detecta en la siguiente sentencia:

El análisis que a propósito de la demanda se ha adelantado le deja a la Corte la convicción de que la legislación electoral vigente no responde a las exigencias surgidas de la regula- ción superior de la materia contenida en la Constitución de 1991 y el desfase se torna todavía más patente después de la reforma constitucional adoptada mediante el Acto Legislativo No. 01 de 2003. (...). En cuanto hace a la organización electoral, sin pretender una indicación exhaustiva de las materias que ameritan una nueva regulación legislativa, el examen que la Corte ha realizado permite sostener que es necesario definir legalmente el modelo de organización electoral adoptado, señalar la naturaleza jurídica, el objeto y la conformación del Consejo Nacional Electoral y de la Registraduría Nacional del Estado Civil, establecer las funciones de cada uno de estos organismos, sentar las bases de las relaciones que deben existir entre ellos y precisar el sentido y el alcance de la función de inspección y vigilancia asignada al Consejo Nacional Electoral. Tratándose de la función pública en el seno de la Registraduría Nacional del Estado Civil es claro que del estudio adelantado por la Corporación cabe concluir que se requiere concretar cuanto antes los mandatos constitucionales en materias tales como las modalidades de vinculación, la clasificación de los distintos servidores públicos, el señalamiento de los cargos de responsabilidad administrativa y electoral, el régimen de ingreso, la carrera administrativa especial, las situaciones administrativas y el retiro, en especial el flexible al cual se refiere el artículo 266 superior, entre otros temas. (CConst., C-230A/2008, R. Escobar).

4. En esta sentencia se demandó la inconstitucionalidad de ciertas normas del régimen de testamentos en las que se excluía la referencia a las parejas del mismo sexo como partes de este régimen, en relación con la figura de la porción conyugal. 
En esta decisión la Corte no solo se limitó a describir algunas de las cuestiones necesarias de tener en cuenta por el legislador para regular el funcionamiento de los órganos electorales del país, sino que además le impuso un plazo (16 de diciembre de 2008) para que desarrollara la reglamentación solicitada, con el fin de sintonizar la normatividad electoral con las disposiciones constitucionales, en especial con el Acto Legislativo No. 01 de 2003.

Sin embargo, la ausencia de una estirpe normativa para esta clase de plazos o de medidas más imperativas impide que la Corte pueda controlar la forma como estos mandatos son acogidos por el órgano legislativo y devuelve la discusión al problema de la efectividad de la medida. $^{5}$

\section{La Corte activista: ¿desafiando la esfera del legislador?}

Una última actitud que se evidencia en algunos exhortos al legislador efectuados por la Corte Constitucional colombiana refleja visos de activismo judicial, es decir, una postura más decidida a remediar de manera directa la omisión inconstitucional detectada. A pesar de que la Constitución no autoriza expresamente la utilización de mecanismos para lidiar con las omisiones legislativas inconstitucionales, al interior del alto tribunal se ha diseñado un catálogo de soluciones en las que el exhorto viene acompañado de otra serie de elementos que reflejan un rol más protagónico de la Corte. Roles que inclusive pueden llegar a desafiar la esfera de competencias del órgano legislativo.

En algunas oportunidades, el tribunal no ha considerado como una alternativa compatible con la defensa de la Constitución el "sentarse a esperar" a que el legislador decida proferir la normatividad sobre los vacíos, las omisiones o las indeterminaciones detectadas, especialmente cuando estos defectos afectan ciertos derechos fundamentales. En estos casos, la Corte ha combinado el exhorto al legislador con otra clase de formulaciones en las que mediante su intervención directa es posible, en asuntos concretos, solucionar las omisiones inconstitucionales.

Una de estas formulaciones en las que la Corte colombiana ha desplegado actitudes más activistas para solucionar las omisiones legislativas inconstitucionales consiste en la combinación del exhorto con decisiones de carácter aditivo en las que incorpora los enunciados necesarios para completar la disposición deficitaria, a la luz del texto constitucional. Esta fórmula fue utilizada en decisiones como la

5. Sobre el particular Ferrajoli (2011) señala: “Naturalmente, cabe imaginar garantías constitucionales secundarias de tipo jurisdiccional para poner coto no solo a las antinomias sino incluso a las lagunas: no solo, por tanto, a las violaciones de la constitución por acción sino también de las violaciones por omisión, a través de la extensión a estas del juicio de ilegitimidad constitucional. Desgraciadamente, tal extensión encuentra un límite en la naturaleza de la condena y prevención o de anulación del acto ilícito o inválido objeto de la comprobación jurisdiccional. También el juicio sobre una laguna puede ser configurado como una comprobación de un incumplimiento. A diferencia de la anulación y de la condena, sin embargo, es difícil prefigurar sus efectos concretamente reparadores" (p. 94). 
Sentencia C-221 de 1997 (reseñada en la tabla 2), la Sentencia C-684 de 2009 (reseñada en la tabla 3) o en la Sentencia C-720 de 2007. En esta última, la Corte se pronunció sobre la constitucionalidad de ciertas normas del Código de Policía que facultaban la retención de personas por miembros de la Policía sin autorización judicial y hasta por un término de 24 horas. La demanda de la norma se fundamentó en la oposición del artículo 28 de la CP, que consagra la libertad personal. En esta decisión la Corte declaró la inconstitucionalidad de la norma demandada pero difirió los efectos de su fallo en el tiempo hasta el día 20 de junio de 2008. Sin embargo, lo interesante de la decisión es que el alto tribunal estableció una serie de prerrequisitos, que deberían tomar en consideración los miembros de la Policía, al efectuar retenciones transitorias durante el plazo establecido para que surtiera efecto la declaratoria de inconstitucionalidad o mientras el legislador expedía la regulación respectiva. Dijo la Corte:

En todo caso, y hasta tanto el Congreso de la República regule la materia de conformidad con lo resuelto en el ordinal anterior, la retención transitoria solo podrá aplicarse cuando sea estrictamente necesario y respetando las siguientes garantías constitucionales: i) se deberá rendir inmediatamente informe motivado al Ministerio Público, copia del cual se le entregará inmediatamente al retenido; ii) se le permitirá al retenido comunicarse en todo momento con la persona que pueda asistirlo; iii) el retenido no podrá ser ubicado en el mismo lugar destinado a los captura- dos por infracción de la ley penal y deberá ser separado en razón de su género; iv) la retención cesará cuando el retenido supere el estado de excitación o embriaguez, o cuando una persona responsable pueda asumir la protección requerida, y en ningún caso podrá superar el plazo de 24 horas; v) los menores deberán ser protegidos de conformidad con el Código de la Infancia y la Adolescencia; vi) los sujetos de especial protección constitucional solo podrán ser conducidos a lugares donde se atienda a su condición. (CConst., C-720/2007, C. Botero).

La Corte decidió adicionar la norma relacionada con retenciones transitorias por considerar que aunque el enunciado normativo demandado resultaba contrario al artículo 28 de la $\mathrm{CP}$, existían ciertas circunstancias en las que la medida de retención transitoria resultaba necesaria para proteger la vida o integridad de las personas, como por ejemplo de quienes sufren de trastornos metales. Sin embargo, condicionó el uso de la medida de retención transitoria a una serie de prescripciones que complementaban la norma para armonizarla con la Constitución.

El tono de la Corte en esta clase de decisiones es activista, pues en ellas muestra una cierta desconfianza acerca de si el legislador finalmente va a desplegar las acciones necesarias para remediar las omisiones inconstitucionales denunciadas. Por ello interviene directamente combinando la exhortación con la formulación de soluciones que remedien la omisión detectada. 
Otro registro de activismo se observa en la solución dada en la Sentencia C-728 de 2009, en relación con la objeción de conciencia para el servicio militar obligatorio; también en el dictamen acerca del reconocimiento del matrimonio para parejas del mismo sexo, de acuerdo con los términos de la Sentencia C-577 de 2011. En estos casos, para dar solución a la omisión legislativa o al déficit de protección constitucional, ${ }^{6}$ el tribunal no se conformó con realizar una exhortación al Congreso sino que, de manera adicional, incluyó en el decisum de estas sentencias una advertencia para que los afectados con la situación inconstitucional que se produce como consecuencia de la omisión puedan hacer uso de la acción de tutela, como mecanismo para lograr la garantía de sus derechos. ${ }^{7}$

Sin embargo, no deja de resultar paradójico que estas actitudes activistas hayan sido desplegadas por la Corte en aquellos escenarios de omisiones derivadas de la interpretación, es decir, en los casos en que la omisión ha surgido como resultado de la interpretación que la misma Corte le ha dado a las normas constitucionales, pero en las que la simple lectura del texto constitucional no da luces en torno a la existencia de la omisión. Si se toma en consideración que fue a partir de la evolución de la jurisprudencia de la Corte acerca del derecho a la objeción de conciencia en la prestación del servicio militar o sobre el reconocimiento de los derechos de las parejas del mismo sexo que se construyó la idea de estas omisiones inconstitucionales, resultaría "cuestionable" la existencia de una limitación a la esfera de lo decidible por parte del legislador.

Estos cuestionamientos se identifican en aqueIlas visiones que critican la posibilidad de controlar las omisiones legislativas, en los términos que se describen a continuación:

El constructo de la omisión inconstitucional, aunque nace del deseo de llevar a las últimas consecuencias el principio de supremacía de la Constitución, puede producir un resultado contrario a ese deseo. Aquí late el problema

6. Es interesante señalar que en el caso de la Sentencia C-577 de 2011 la Corte se abstuvo de utilizar el concepto de omisión legislativa y optó por la expresión "déficit de protección constitucional". En esta sentencia, tal y como ocurrió en la Sentencia C-728 de 2009, los demandantes acusaban la inconstitucionalidad de las normas demandadas bajo el argumento de la existencia de omisiones legislativas de carácter relativo. Mientras que en la sentencia C-728 de 2009 la Corte aceptó que más que una omisión relativa la norma acusada indicaba la existencia de una omisión absoluta en el sistema jurídico colombiano, en el caso de la sentencia C-577 de 2011 prefirió utilizar la expresión "déficit de protección constitucional" que ya había usado en decisiones anteriores, dentro de la línea jurisprudencial que ha venido concediendo derechos a las parejas del mismo sexo.

7. En la Sentencia C-728 de 2009 la Corte hizo explícitas una serie de consideraciones que los jueces de instancia deberían tomar en consideración al resolver estas acciones de tutela, a saber: (i) Las conductas que se pretende proteger mediante la objeción de conciencia deben manifestarse en el comportamiento externo del objetor y no solamente en su fuero interno. Por ello el objetor de conciencia tiene la carga de mostrar cuáles son las convicciones o creencias que se contrarían o afectan con la prestación del servicio militar obligatorio; (ii) estas conductas además deben ser profundas (afectar de manera integral la vida y personalidad del objetor), fijas (no modificables con facilidad) y sinceras (no ser estratégicas o acomodaticias) y esta situación también debe probarse por el objetor; (iii) La objeción de conciencia puede aducirse por razones religiosas, éticas, morales o filosóficas. Lo anterior implica que la objeción de conciencia no necesariamente se puede invocar alegando creencias religiosas, sino que se puede hacer uso de otra serie de convicciones humanas para solicitar su protección. 
de la interpretación de la Constitución. Porque esta es la cuestión, en qué medida bajo la invocación retórica de la "supremacía de la Constitución", en la práctica no se produce una subrepticia consagración de la supremacía del tribunal Constitucional, convertido en la práctica en el titular del poder constituyente. (Ruiz Miguel, 2004 p. 174).

La anterior crítica se vuelve poderosa si se toma en consideración que la lectura expresa de las disposiciones constitucionales relacionadas con estas materias sirvió de sustento para que, en sus inicios, estos problemas jurídicos no fueran tratados como omisiones legislativas inconstitucionales. Así, en su jurisprudencia temprana, la misma Corte acudió a la cláusula de cierre del sistema para negar los recursos de amparo en los que personas afectadas reclamaban por vía de tutela la protección del derecho a objetar, por razones de conciencia, la prestación del servicio militar, o a reconocer la existencia de omisiones inconstitucionales por el desconocimiento de la posibilidad de otorgar efectos civiles a la conformación de parejas del mismo sexo.

La paradoja, entonces, se desenvolvería si el legislador reconoce las nuevas interpretaciones de la Corte en materia de estos derechos fundamentales y acepta la existencia de omisiones inconstitucionales, pero crea una solución divergente a la adoptada por el alto tribunal. Por ejemplo, si llegara a expedir una legislación para regular la objeción de conciencia pero mucho más restrictiva que la solución establecida por la Corte, como sería limitar la objeción a motivos eminentemente religiosos, ${ }^{8}$ o legislar pero para declarar la inexistencia de una omisión inconstitucional sobre estos asuntos. ¿Cómo enfrentaría la Corte el desafío del legislativo?

Tal y como se vio, en las omisiones inconstitucionales derivadas del texto expreso de la Constitución, en las que el deber del legislador de proferir una determinada regulación para hacer efectivos los contenidos de una disposición constitucional es más evidente, la Corte ha mostrado más deferencia con la competencia del legislador, sus exhortos son más prudentes y ha llegado a reiterar en varias oportunidades el llamado pero con actitudes de autocontención en relación con la solución a la omisión detectada.

Si estas actitudes se contrastan con las asumidas frente a omisiones derivadas de la interpretación surgen interrogantes en torno a si la retórica activista que despliega la Corte se identifica con la defensa de la supremacía de la Constitución o con la defensa de la supremacía de sus propias decisiones.

Esta pregunta bien podría tener respuestas en el discurso desplegado por la propia Corte

8. Recuérdese que en la Sentencia C-728 de 2009 la Corte señaló la posibilidad de que se invoque la objeción de conciencia por motivos éticos o filosóficos y no solo por motivos religiosos. 
cuando hace uso de tonos activistas como mecanismo para controlar las omisiones legislativas inconstitucionales. En otros términos, la Corte podría justificar su intervención más desafiante con el argumento de que los derechos fundamentales desprotegidos por la omisión vulneran las formas de vida de miembros de grupos tradicionalmente subrepresentados, que por sus condiciones históricas de discriminación o por defender posturas contrarias a las de las mayorías sociales tienen poco chance de lograr que las acciones y causas que provocan la afectación de sus derechos sean erradicadas mediante la expedición de medidas legislativas proferidas en el seno del cuerpo legislativo.

Sin embargo, la Corte en las decisiones analizadas no realiza esta clase de reflexiones, y más bien de manera velada combina la técnica del exhorto con otra serie de condiciones en las que interviene más directamente para solucionar la omisión legislativa inconstitucional. Pero la ausencia de sinceridad en las razones de la Corte hace que las respuestas a las preguntas acerca del futuro de estas decisiones, en el seno de lo político, no sean fácilmente determinables.

\section{CONCLUSIONES}

La normatividad constitucional colombiana no tiene prevista ninguna clase de control o mecanismo para remediar los silencios legislativos generadores de omisiones inconstitucionales. No obstante lo anterior, en el orde- namiento jurídico se ha iniciado la discusión sobre la posibilidad de limitar la esfera de lo decidible por el legislador mediante el control de las omisiones inconstitucionales. En esta discusión, la Corte Constitucional, desde los inicios de su actividad como guardiana de la integridad y de la supremacía de la Constitución, ha jugado un rol protagónico mediante su jurisprudencia, y además ha utilizado distintos mecanismos para remediar los silencios del legislador que producen omisiones inconstitucionales, dentro de los que se destaca la figura del exhorto.

Ahora bien, el uso del exhorto por parte de la Corte colombiana no ha logrado controlar la renuencia o la negligencia del legislador a decidir lo necesario para garantizar los contenidos del texto constitucional, situación que impide evaluar hasta qué punto se está transformando la esfera de acción legislativa mediante dicha figura. Lo que sí es posible sostener es que el exhorto, en los distintos escenarios en los que ha sido utilizado por la Corte colombiana, ha tenido la pretensión de "provocar" reacciones del legislativo frente a la configuración de los derechos constitucionales.

Sin embargo, el estilo de tales provocaciones no ha sido unívoco ni consistente y ha variado acorde con el escenario constitucional en el que decide la Corte. Así, sus exhortos van desde respetuosas y prudentes recomendaciones al legislador, en los que parece más una consejera que busca que este solucione omisiones legislativas detectadas o producidas por la declaratoria de inconstitucionalidad de una 
norma jurídica determinada, hasta actitudes de talante más activista que inclusive pueden considerarse una invasión a la órbita de competencia legislativa por cuanto impone plazos o imparte órdenes para que se detengan las situaciones que afectan derechos, acudiendo directamente a los tribunales judiciales.

Por este motivo, la respuesta a los interrogantes en relación con la forma como en el ordenamiento jurídico colombiano se controlan los silencios legislativos que originan omisiones legislativas inconstitucionales aún no está clara. Es necesario examinar la manera como en el Congreso colombiano se han recibido estos intentos de control. En este orden de ideas resulta imperioso determinar si los exhortos al legislador están siendo vistos como una fuente de colaboración armónica entre las ramas, o como indebida intromisión de una Corte demasiado activista en el desarrollo de las tareas legislativas. Solo en la medida en que se clarifiquen estas reacciones se avanzará en la respuesta a estos interrogantes.

\section{Referencias}

1. Bazán, V. (2003). Respuestas normativas y jurisdiccionales frente a las omisiones inconstitucionales. Una visión de derecho comparado. En M. Carbonell (Ed.), En busca de las normas ausentes. Ensayos sobre la inconstitucionalidad por omisión (pp. 92-287). México: Universidad Nacional Autónoma de México.
2. Bulnes, L. (2006). La inconstitucionalidad por omisión. Estudios Constitucionales, 4(1), 251-264.

3. Corte Constitucional de Colombia. Sentencia C-473/1994 (M. P.: Alejandro Martínez Caballero; octubre 27 de 1994).

4. Corte Constitucional de Colombia. Sentencia C-690/1996 (M. P.: Alejandro Martínez Caballero; diciembre 5 de 1996).

5. Corte Constitucional de Colombia. Sentencia C-221/1997 (M. P.: Alejandro Martínez Caballero; abril 29 de 1997).

6. Corte Constitucional de Colombia. Sentencia C-239/1997 (M. P.: Carlos Gaviria Díaz; mayo 20 de 1997).

7. Corte Constitucional de Colombia. Sentencia C-699/2007 (M. P.: Rodrigo Escobar Gil; septiembre 6 de 2007).

8. Corte Constitucional de Colombia. Sentencia C-720/2007 (M. P.: Catalina Botero Marino; septiembre 11 de 2007).

9. Corte Constitucional de Colombia. Sentencia C-230A/2008. (M. P.: Rodrigo Escobar Gil; marzo 6 de 2008)..

10. Corte Constitucional de Colombia. Sentencia C-798/2008 (M. P.: Jaime Córdoba Triviño; agosto 20 de 2008). 
11. Corte Constitucional de Colombia. Sentencia C-684/2009 (M. P.: Humberto Antonio Sierra Porto; junio 17 de 2009).

12. Corte Constitucional de Colombia. Sentencia C-728/2009 (M. P.: Gabriel Eduardo Mendoza Martelo; octubre 14 de 2009).

13. Corte Constitucional de Colombia. Sentencia C-283/2011 (M. P.: Jorge Ignacio Pretelt Chaljub; abril 13 de 2011).

14. Corte Constitucional de Colombia. Sentencia C-577/2011 (M. P.: Gabriel Eduardo Mendoza Martelo; julio 26 de 2011).

15. Corte Constitucional de Colombia. Sentencia C-366/2011 (M. P.: Luis Ernesto Vargas Silva; mayo 11 de 2011).

16. Fernández, J. (2003). Aproximaciones al concepto de inconstitucionalidad por omisión. En M. Carbonell (Ed.), En busca de las normas ausentes. Ensayos sobre la inconstitucionalidad por omisión (pp. 1764). México: Universidad Nacional Autónoma de México.

17. Ferrajoli, L. (2011). Principia iuris. Teoría del derecho y de la democracia (Vol. 3). Madrid: Editorial Trotta.

18. Ramírez Cleves, G. (2006). El control de constitucionalidad sobre las omisiones legislativas en Colombia. Obtenido de icr. uexternado: http://icr.uexternado.edu.co/ Documentos/ponencia1.pdf

19. Ruiz Miguel, C. (2004). Crítica de la llamada inconstitucionalidad por omisión. Revista Iberoamericana de Derecho Procesal (2), 159-177.

20. Sagüés, N. (2007). Problemas constitucionales en la solución de la inconstitucionalidad por omisión. En Cuadernos Constitucionales de la Cátedra Fadrique Furió Ceriol, (58/59), 253-264.

21. Sarmiento, J. (2010). La modulación de las sentencias de la Corte Constitucional: ¿Juez natural para la responsabilidad del Estado legislador? Revista Precedente, 227-258.

22. Villaverde, I. (2003). La inconstitucionalidad por omisión un nuevo reto para la justicia constitucional. En M. Carbonell (Ed.), En busca de las normas ausentes. Ensayos sobre la inconstitucionalidad por omisión (pp. 65-91). México: Universidad Nacional Autónoma de México.

23. Waldron, J. (2006). The Core of the Case Against Judicial Review. The Yale Law Journal, (115), 1346-1406. 